\title{
Transparent conductive aluminium and fluorine co-doped zinc oxide films via aerosol assisted chemical vapour deposition
}

Sapna D. Ponja, Sanjayan Sathasivam, Ivan P. Parkin and Claire J. Carmalt*

${ }^{*}$ Corresponding author

Materials Chemistry Centre, Department of Chemistry, University College London, 20 Gordon Street, London, WC1H OAJ, UK

E-mail: c.j.carmalt@ucl.ac.uk

\begin{abstract}
Aerosol assisted chemical vapour deposition (AACVD) was employed to synthesise highly transparent and conductive $\mathrm{ZnO}$, fluorine or aluminium doped and aluminiumfluorine co-doped $\mathrm{ZnO}$ thin films on glass substrates at $450{ }^{\circ} \mathrm{C}$. All films were characterised by $\mathrm{X}$-ray diffraction (XRD), wavelength dispersive $\mathrm{X}$-ray spectroscopy (WDX), X-ray photoelectron spectroscopy (XPS), scanning electron microscopy (SEM) and UV/Vis/Near IR spectroscopy. The films were 300-350 nm thick, crystalline and displayed high transparency at $550 \mathrm{~nm}$ (80-90\%). The co-doped film consisted of 1 at.\% fluorine and 2 at.\% aluminium, exhibiting a charge carrier concentration and a charge carrier mobility of $3.47 \times 10^{20} \mathrm{~cm}^{-3}$ and $9.7 \mathrm{~cm}^{2} \mathrm{~V}^{-1} \mathrm{~s}^{-1}$, respectively. The band gap of the co-doped film was found to be $3.7 \mathrm{eV}$ and the plasma edge crossover was ca. $1800 \mathrm{~nm}$. This film had a highly structured morphology in comparison to the un-doped and single doped $\mathrm{ZnO}$ films for transparent conducting oxide applications.
\end{abstract}




\section{Introduction}

Transparent conducting oxides (TCO) have applications in optoelectronic devices such as flat panels, solar cells and light emitting diodes (LEDs). ${ }^{1,2}$ TCO's are best described as having a transmittance above $80 \%$ in the visible spectrum characterised by a bandgap of greater than $3.1 \mathrm{eV}$ and an electrical resistivity of no more than $10^{-3} \Omega \mathrm{cm} ;{ }^{3}$ hence they are optically transparent materials with high electrical conductivity. The electrical conductivity is a consequence of the number of available charge carriers (preferably $10^{20} \mathrm{~cm}^{-3}$ or higher) and their mobility. ${ }^{3,4}$ To be transparent and conductive would normally be contradictory since transparency requires a wide bandgap which would otherwise hinder the formation of charge carriers thus a compromise of the two is required. A number of factors affect the bandgap of semiconductors including the addition of a dopant. ${ }^{5}$ Doping increases the carrier concentration in order to achieve greater conductivity. It can also widen or narrow the bandgap particularly at high doping concentrations. ${ }^{6,7}$ However, over doping is not desirable as it has a detrimental effect on conductivity as a result of deterioration in the film structure leading to a reduction in the mobility of the free electrons. ${ }^{8,9}$

The most widely used commercial TCO films have been made using indium or tin based oxides. ${ }^{3}$ Tin doped Indium oxide (ITO) is the most commonly produced TCO followed by fluorine doped tin oxide (FTO). ${ }^{10}$ However, indium is in limited supply and relatively expensive, and the price of tin has risen rapidly in the past few years. ${ }^{11}$ Thus, there is a need to find alternative materials that can be employed in optoelectronic devices. Zinc oxide films have been recognised as suitable alternatives based on the low cost, greater earth abundance and comparable optoelectronic properties. ${ }^{12,13,14}$

Zinc oxide with a wurtzite structure is a wide bandgap semiconductor $(3.3 \mathrm{eV}) .^{12}$ The incorporation of dopants into the $\mathrm{ZnO}$ lattice is known to alter its properties ${ }^{15}$ for example fluorine is known to improve electrical conductivity. ${ }^{13}$ Fluorine is incorporated into the lattice by substituting an $\mathrm{O}^{2-}$ site with $\mathrm{F}^{-}\left(\mathrm{O}^{2-:}: 1.24 \AA\right.$; $\mathrm{F}^{-}: 1.17 \AA$ ) resulting in one more free electron making fluorine a suitable dopant for $n$-type 
conductivity. ${ }^{16}$ The incorporation of group III elements into the $\mathrm{ZnO}$ lattice has also received much attention. ${ }^{17,18,19,20,21}$ Aluminium doped $\mathrm{ZnO}$ films involve $\mathrm{Al}^{3+}(0.54 \AA$ ) occupying a $\mathrm{Zn}^{2+}(0.74 \AA)$ site leading to a reduction in the lattice parameter. Gallium doped $\mathrm{ZnO}$ films are known to have better electrical properties as the ionic radius of $\mathrm{Ga}^{3+}$ is similar to that of $\mathrm{Zn}^{2+}$, minimizing deformation. ${ }^{13,22}$ However, the drawback of gallium is its relatively low durability in high humidity atmosphere and a higher cost implication in commercial production. ${ }^{17}$ Co-doping with aluminium has the potential to minimise the lattice distortion and lead to TCO $\mathrm{ZnO}$ materials with enhanced figures of merit. ${ }^{13}$

A variety of methods have been used to deposit $\mathrm{ZnO}$ thin films including chemical vapour deposition (CVD), sputtering, sol-gel and spray pyrolysis. ${ }^{13,23}$ This paper focuses on thin films of $\mathrm{ZnO}, \mathrm{F}: \mathrm{ZnO}, \mathrm{Al}: \mathrm{ZnO}$ and uniquely Al:F:ZnO deposited via Aerosol Assisted CVD using a dual source system. AACVD has advantages over conventional CVD in that the precursors do not have to be volatile or thermally stable, depositions can take place at atmospheric pressure and it provides a potentially low cost method for the mass production of thin films. ${ }^{24,25}$ We report that co-doping $\mathrm{ZnO}$ films enhances the electrical conductivity and optical properties of the resultant films. Furthermore, and quite surprisingly, it was found that low levels of doping imparted microstructures that were near ideal for TCO applications in silicon solar cells. 


\section{Experimental Details}

The following chemicals were purchased from Sigma-Aldrich: diethyl zinc (1.1 $\mathrm{M}$ in toluene), trimethyl aluminium (2.0 $\mathrm{M}$ in toluene) and ammonium fluoride $(98 \%)$. Toluene was purchased from Fisher Scientific and stored under alumina columns and dried with Anhydrous Engineering equipment. Methanol (MeOH; 99.99\% Fischer Scientific) was dried by distillation over magnesium turnings before use. Nitrogen gas $(\geq 99.9 \%)$ was used as-supplied from BOC. The glass substrate was standard float glass, with a $50 \mathrm{~nm}$ thick $\mathrm{SiO}_{2}$ barrier layer, supplied by Pilkington NSG.

Caution! All experiments should be carried out in a fume hood. ZnEt2 and $\mathrm{AlMe}_{3}$ are pyrophoric and hence the CVD of these chemicals can potentially be toxic and corrosive.

The depositions were carried out in an in-house built CVD rig (supplementary information). The deposition of the $\mathrm{ZnO}$ film was achieved by transferring dry toluene $(25 \mathrm{~mL})$ to diethyl zinc $(1.82 \mathrm{~mL})$ into one Drechsel bottle and dry methanol $(40 \mathrm{~mL})$ into the second bottle. Nitrogen gas was bubbled through the solutions and aerosols were generated using Vicks ultrasonic humidifiers (Eq. 1). Films doped with fluorine were produced by adding ammonium fluoride $(0.0075 \mathrm{~g})$ to the Drechsel bottle containing methanol (Eq. 2) but when doping with aluminium, trimethyl aluminium $(1.5 \mathrm{~mL})$ was added to the same bottle as the diethyl zinc (Eq. 3). When co-doping, both dopants were used in the respective Drechsel bottles at the same time (Eq. 4). The deposition was started by heating the bottom substrate to $450{ }^{\circ} \mathrm{C}$ under a low flow rate of nitrogen gas, monitored and controlled using a flow rate meter. The aerosols of both precursor solutions were then diverted through the $\mathrm{Y}$-junction where they mixed before entering the baffle at a fixed flow rate $\left(1.0 \mathrm{~L} \mathrm{~min}^{-1}\right)$. Once the precursor solutions were completely used up, nitrogen gas, at a reduced flow rate, was passed through into the chamber until the film reached room temperature. The plate was then removed for analysis. 


\section{Film analysis}

X-ray diffraction (XRD) measurements were obtained using a modified Bruker-Axs D8 diffractometer with parallel beam optics equipped with a PSD LynxEye silicon strip detector to collect diffracted X-ray photons. X-rays were generated using a $\mathrm{Cu}$ source with $\mathrm{Cu}$ Ka1 and $\mathrm{Cu}$ Ka2 radiation of wavelengths 1.54056 and $1.54439 \AA$, respectively, emitted with an intensity ratio of $2: 1$, a voltage of $40 \mathrm{kV}$, and current of $30 \mathrm{~mA}$. The incident beam angle was kept at $1^{\circ}$, and the angular range of the patterns collected was $10^{\circ}<2 \theta<66^{\circ}$ with a step size of $0.05^{\circ}$ counted at $0.5 \mathrm{~s} / \mathrm{step}$. The patterns were analysed for crystallinity and preferred orientation. Peak positions were compared to patterns from the Inorganic Crystal Structure Database (ICDS). The lattice parameters were calculated from powder X-ray diffraction data using the software GSAS and EXPGUI via the Le Bail method.

Wavelength dispersive X-ray (WDX) analysis was carried out on a Phillips ESEM. The $\mathrm{Zn}, \mathrm{Al}$ and $\mathrm{F}$ atom\% was derived from $\mathrm{Zn}-\mathrm{K} \alpha$ line (8638 eV), Al-Ka (1487 eV) and F-K $\alpha(6768 \mathrm{eV})$ respectively.

X-ray photoelectron spectroscopy (XPS) analysis of the films were carried out using a Thermo Scientific K-Alpha spectrometer fitted with a monochromatic Al-Ka source to identify chemical constituents by depth profiling. The peaks were modelled using CasaXPS software with binding energies adjusted to adventitious carbon $(284.5 \mathrm{eV})$ in order to compensate for the effects of charging. Survey scans were collected in the range $0-1500 \mathrm{eV}$ (binding energy) at a pass energy of $40 \mathrm{eV}$.

Scanning electron microscopy (SEM) was performed to determine the film morphology from the top-down configuration using a JEOL JSM-6301F Field Emission instrument with accelerating voltages ranging from 3-5 keV on Au-coated samples.

UV/Vis/Near IR transmittance and reflectance spectra were produced using the Perkin Elmer Precisely Lambda 950 spectrometer using an air background and recorded between $320-2500 \mathrm{~nm}$. 
Film thicknesses were measured using the Filmetrics F20 machine operating in reflectance mode in air against an as-supplied FTO standard. Hall Effect measurements were carried out on an Ecopia HMS-3000 set up in the Van der Pauw configuration to determine the sheet resistance, free carrier concentration $(N)$ and mobility $(\mu)$. Samples of $1 \mathrm{~cm}^{2}$ were prepared and silver paint (Agar Scientific) was used to form ohmic contacts which were tested on the in-built software prior to measurement. The samples were then subjected to an input current of $1 \mathrm{~mA}$ and a calibrated magnetic field of $0.58 \mathrm{~T}$. 


\section{Results and Discussion}

Thin films of $\mathrm{ZnO}$, fluorine doped $\mathrm{ZnO}$, aluminium doped $\mathrm{ZnO}$ and aluminium-fluorine co-doped $\mathrm{ZnO}$ were deposited on glass substrates at $450{ }^{\circ} \mathrm{C}$ using AACVD. The undoped $\mathrm{ZnO}$ films were produced from the CVD reaction of diethylzinc (delivered in a toluene aerosol) with a methanol aerosol (oxygen source) and the doped/co-doped films were accomplished by the addition of ammonium fluoride (in a methanol aerosol) or/and trimethylaluminium (in a toluene aerosol) to the diethylzinc solution. These commercially available precursors break down cleanly and lead to stable films with reduced carbon contamination. ${ }^{26}$ The films were highly transparent and conductive with uniform coverage. Furthermore, the films were very adherent passing the scotch tape test.

$$
\begin{aligned}
& \mathrm{ZnEt}_{2}+\mathrm{MeOH} \underset{\text { dry toluene }}{450^{\circ} \mathrm{C} ; \mathrm{N}_{2}} \mathrm{ZnO} \\
& \mathrm{ZnEt}_{2}+\mathrm{MeOH}+\mathrm{NH}_{4} \mathrm{~F} \frac{\text { dry toluene }}{450^{\circ} \mathrm{C} ; \mathrm{N}_{2}} \mathrm{~F}: \mathrm{ZnO} \\
& \mathrm{ZnEt}_{2}+\mathrm{MeOH}+\mathrm{AlMe}_{3} \frac{\text { dry toluene }}{450^{\circ} \mathrm{C} ; \mathrm{N}_{2}} \mathrm{Al}: \mathrm{ZnO} \\
& \mathrm{ZnEt}_{2}+\mathrm{MeOH}+\mathrm{NH}_{4} \mathrm{~F}+\mathrm{AlMe}_{3} \frac{\text { dry toluene }}{450{ }^{\circ} \mathrm{C} ; \mathrm{N}_{2}} \mathrm{Al}: \mathrm{F}: \mathrm{ZnO}
\end{aligned}
$$

$\mathrm{XRD}$ showed that all the films were single phase $\mathrm{ZnO}$ with reflections at 31.8, 34.5, $36.3,47.5,56.6$ and 62.920 degrees corresponding to the (100), (002), (101), (102), (110) and (212) planes, respectively (Fig. 1.). Preferred orientation was determined through texture coefficient calculations. ${ }^{27}$ The calculations showed the un-doped $\mathrm{ZnO}$ and co-doped Al:F:ZnO films to have preferred orientations in the (100), (101) and (110) planes. Upon doping with fluorine, only the (101) and (110) planes had preferred orientations whereas doping with aluminium the (002) plane was preferred. This work showed that the texture coefficient could be directly controlled by the dopant. The Al:ZnO film gave the XRD pattern with the most noise which is presumed to be due to the film being slightly thinner than the others (Table 2). The preferred orientation of $\mathrm{ZnO}$ is commonly reported as being the (002) plane but there are also papers that have found the (101) plane to be preferred. This difference has 
been attributed to several factors. ${ }^{12,19,28,29,30}$ Waugh et al. ${ }^{12}$ found that increasing the temperature from $400{ }^{\circ} \mathrm{C}$ to $450{ }^{\circ} \mathrm{C}$ changed the preferred orientation from (101) to (002). However, Walters and Parkin found that AACVD deposited ZnO films (using zinc acetylacetonate in methanol) at $400^{\circ} \mathrm{C}$ and $500^{\circ} \mathrm{C}$ both had a dominant (002) peak. ${ }^{28}$ In contrast, a study by Nolan et al. ${ }^{29}$ who also used AACVD to deposit ZnO films (using zinc acetate in methanol) at $425^{\circ} \mathrm{C}$ found the principal peak was (101). Although not tested, the differences between the AACVD studies could be attributed to differences in the precursors used and deposition rates. The method of deposition also has a role to play in the most preferred crystalline orientation for example spray pyrolysis studies ${ }^{19,30}$ have found that at lower temperatures the (002) plane peak is prominent. The average crystallite sizes of the films were calculated using the Scherrer equation and found to be within the range 16-22 nm. ${ }^{31}$ No apparent correlation was found between crystallite size and dopant.

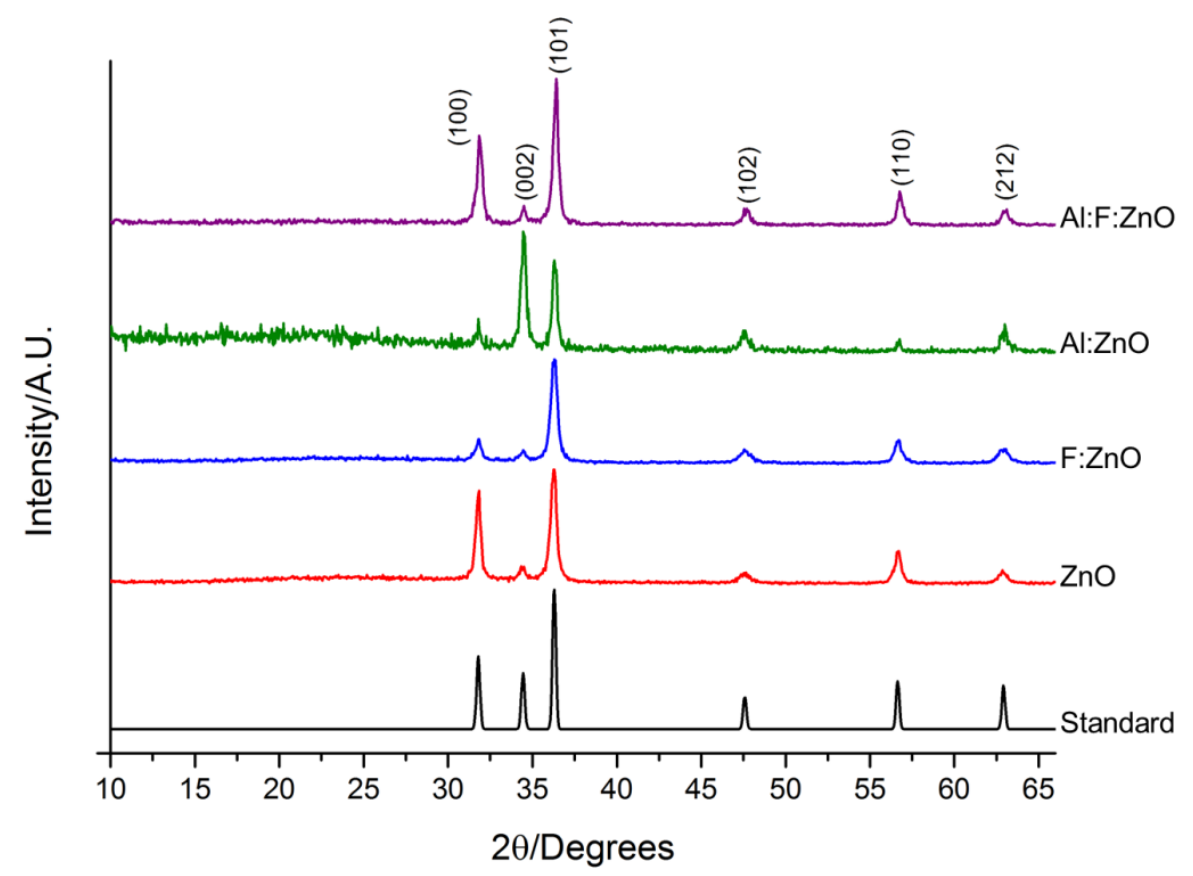

Fig. 1. XRD patterns for the undoped and doped $\mathrm{ZnO}$ films grown using AACVD at $450^{\circ} \mathrm{C}$.

Table 1. Unit cell parameters and dopant concentrations in the doped $\mathrm{ZnO}$ films.

\begin{tabular}{|c|c|c|c|c|c|c|}
\hline Film & $\mathrm{a} / \AA$ & $\mathrm{c} / \AA$ & $\begin{array}{c}\text { Unit cell } \\
\text { volume } / \AA^{3}\end{array}$ & $\begin{array}{c}\text { Volume } \\
\text { contraction / \% }\end{array}$ & $\begin{array}{c}{[\mathrm{F}]} \\
\text { /at.\% }\end{array}$ & $\begin{array}{c}{[\mathrm{Al}]} \\
\text { /at.\% }\end{array}$ \\
\hline $\mathrm{ZnO}$ & $3.2510(2)$ & $5.2145(10)$ & $47.730(9)$ & & & \\
\hline $\mathrm{F}: \mathrm{ZnO}$ & $3.2487(4)$ & $5.209(1)$ & $47.617(9)$ & 0.24 & 1 & \\
\hline $\mathrm{Al}: \mathrm{ZnO}$ & $3.2475(9)$ & $5.207(1)$ & $47.56(2)$ & 0.36 & & 1 \\
\hline $\mathrm{Al}: \mathrm{F}: \mathrm{ZnO}$ & $3.2421(3)$ & $5.202(1)$ & $47.36(1)$ & 0.78 & 1 & 2 \\
\hline
\end{tabular}


Table 1 shows the unit cell parameters of the $\mathrm{ZnO}$ films. The unit cell volume of the undoped $\mathrm{ZnO}$ film had expanded by $0.23 \%$ compared with the standard which can be attributed to strain caused by the amorphous substrate. ${ }^{32}$ The addition of dopants resulted in a minor contraction compared with the $\mathrm{ZnO}$ film which would be expected as both dopants have smaller ionic radii. The contraction was relatively greater when doping with $\mathrm{Al}$ as the difference in the ionic radii between $\mathrm{Al}^{3+}$ and $\mathrm{Zn}^{2+}(0.54 \AA$ and $0.74 \AA$, respectively) is greater than the difference between $\mathrm{F}^{-}$and $\mathrm{O}^{2-}(1.17 \AA$ and $1.24 \AA$, respectively).

Wavelength dispersive X-ray was used to quantify the amounts of dopant being incorporated into the films. This analysis technique reflects the average of the bulk material as the $\mathrm{X}$-rays penetrate several microns deep into the film. Al and $\mathrm{F}$ were present at 1 at.\% in the Al- or F-doped ZnO films and at 2 at.\% and 1 at.\% in the codoped Al:F:ZnO film, respectively (Table 1). Films produced using higher doping concentrations of $\mathrm{Al}$ have been previously shown to form layers of $\mathrm{Al}_{2} \mathrm{O}_{3}$ on the surface. ${ }^{21}$ The actual concentrations are dependent on the method and temperature of deposition, including the atmospheric conditions. ${ }^{21,33}$

$X$-ray photoelectron spectroscopy was performed on the surface of the un-doped and doped $\mathrm{ZnO}$ films to determine the oxidation state of $\mathrm{Zn}$. The un-doped $\mathrm{ZnO}$ films showed a $\mathrm{Zn} 2 \mathrm{p}_{3 / 2}$ peak at $1021.5 \mathrm{eV}$ corresponding to $\mathrm{Zn}^{2+}$. This matched well with a $\mathrm{ZnO}$ standard powder $\left(\mathrm{Zn} 2 \mathrm{p}_{3 / 2}\right.$ peak at $1021.3 \mathrm{eV}$ ) and literature findings (1021.2 eV). ${ }^{34}$ The Al:ZnO films also showed the $Z n p_{3 / 2}$ peak, observed at $1021.1 \mathrm{eV}$, matching well with the standard and literature. ${ }^{34}$ The F:ZnO film and the Al:F:ZnO

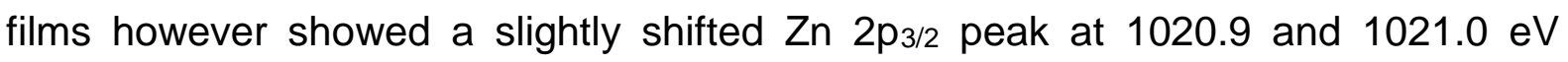
respectively, possibly due to the presence of $\mathrm{F}$ in the $\mathrm{ZnO}$ matrix. Depth profiling of the films showed that the Al was not surface segregated (Fig. 2). The aluminium was found to initially increase but then remain relatively consistent throughout the bulk of the film. 


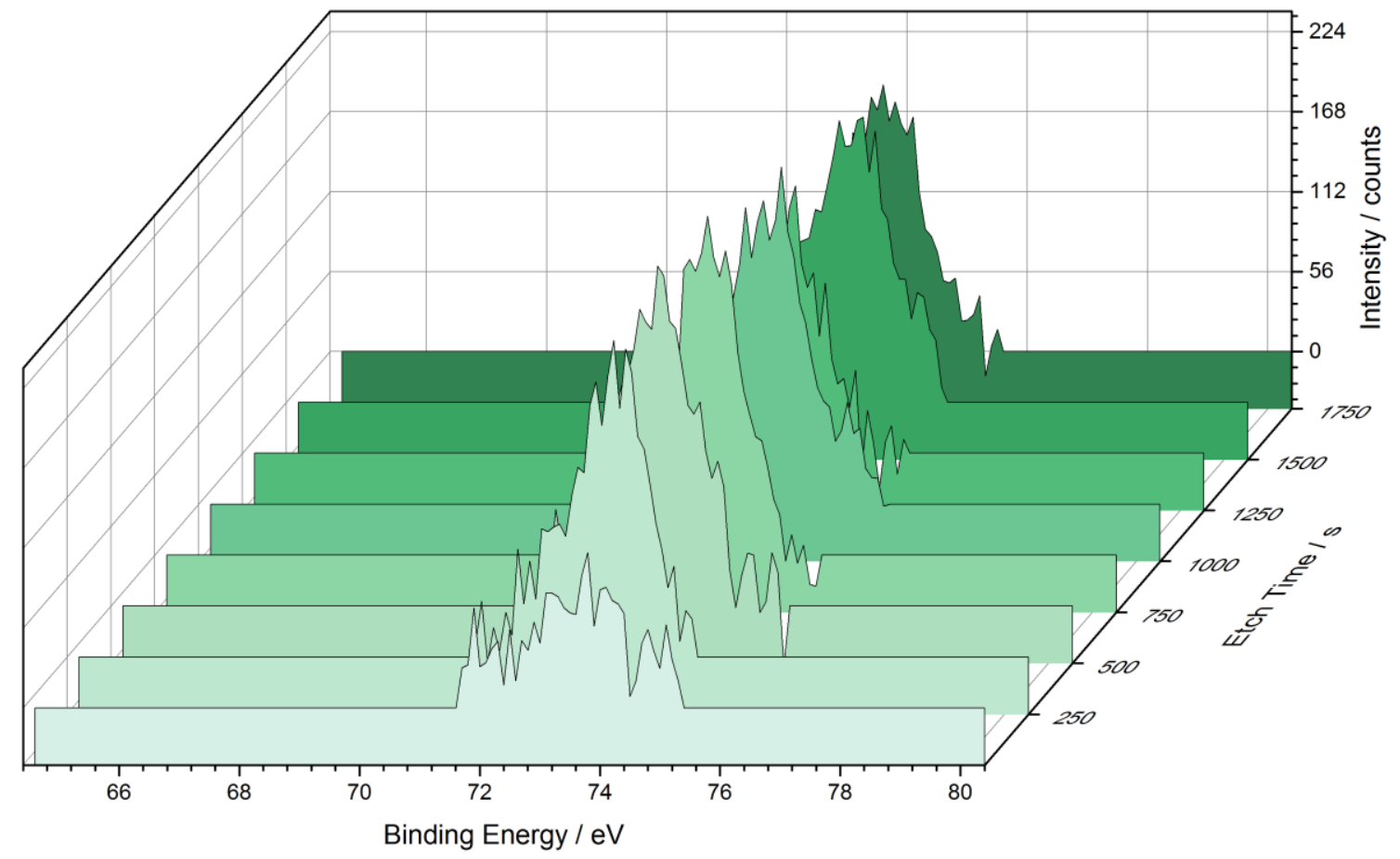

Fig. 2. XPS depth profiling of the co-doped Al:F:ZnO film showing the aluminium content as a function of etch time.

The morphology of the un-doped and doped ZnO films were studied using SEM. The pure $\mathrm{ZnO}$ film (Fig. 3a.) had a dense morphology with large features present in the areas analysed. Upon doping with fluorine the morphology remains compact and dense with small spherical particles. The addition of Al dopant changes the surface of the films dramatically to consist of protruding plate like features that are roughly $200 \mathrm{~nm}$ long (Fig. 3c and d). 


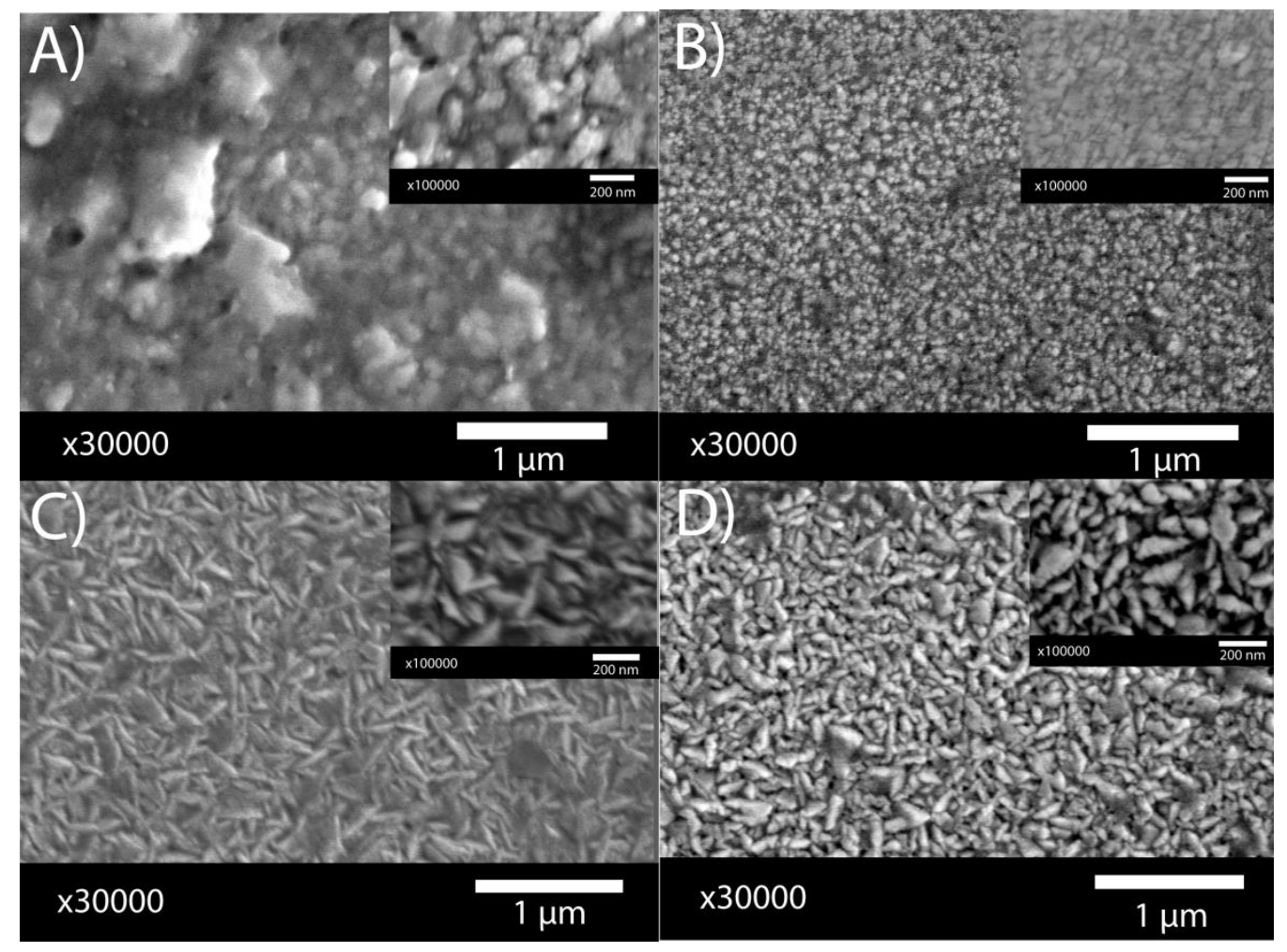

Fig. 3. SEM images showing the morphologies of the films grown via AACVD at $450{ }^{\circ} \mathrm{C}$ using diethylzinc, methanol, ammonium fluoride and trimethylaluminium: (a) ZnO (b) F:ZnO (c) Al:ZnO (d) $\mathrm{Al}: \mathrm{F}: \mathrm{ZnO}$.

Table 2. Hall effect measurements.

\begin{tabular}{|c|c|c|c|c|c|}
\hline Film & $d / \mathrm{nm}$ & $n / \times 10^{20} \mathrm{~cm}^{-3}$ & $\mu / \mathrm{cm}^{2} \mathrm{~V}^{-1} \mathrm{~s}^{-1}$ & $\rho / \times 10^{-3} \Omega \mathrm{cm}$ & $R_{\mathrm{sh}} / \Omega / \square$ \\
\hline $\mathrm{ZnO}$ & 350 & 1.25 & 23.1 & 2.16 & 61.7 \\
\hline $\mathrm{F}: \mathrm{ZnO}$ & 350 & 3.02 & 12.5 & 1.66 & 47.3 \\
\hline $\mathrm{Al}: \mathrm{ZnO}$ & 300 & 2.48 & 11.7 & 2.15 & 71.7 \\
\hline $\mathrm{Al}: \mathrm{F}: \mathrm{ZnO}$ & 350 & 3.47 & 9.7 & 1.85 & 52.8 \\
\hline
\end{tabular}

$d$, film thickness; $n$, charge carrier concentration; $\mu$, charge carrier mobility; $\rho$, bulk resistivity; $R_{\mathrm{sh}}$, sheet resistance

Hall effect measurements were carried out at room temperature using the van der Pauw technique (Table 2). These films were identified as $n$-type from the negative Hall coefficients. The charge carrier concentration increased with $F$ or Al dopant which is expected as both dopants are donors and contribute electrons when substituted. Co-doping further increases the carrier concentration. As expected, there was a reduction in carrier mobility with doping. The F concentration in the codoped film remained the same but the Al doubled to 2 at.\%; this level of doping has been shown to produce the optimum conductivity when $\mathrm{Al}: \mathrm{ZnO}$ films were deposited 
by other methods. ${ }^{35}$ Although the co-doped film had a slightly higher sheet resistance compared with the $\mathrm{F}: \mathrm{ZnO}$ film, the optical properties were significantly enhanced (see below).

The transmission and reflectance properties of the films were investigated using visible/near IR spectrometry. (Fig. 4.) Optical band gap values were calculated via the Tauc plot method. ${ }^{36}$ Un-doped $\mathrm{ZnO}$ had the expected value of $3.3 \mathrm{eV}$. F:ZnO and $\mathrm{Al}: \mathrm{ZnO}$ had a bandgap of $3.6 \mathrm{eV}$ whereas the band gap of the co-doped $\mathrm{Al}: \mathrm{F}: \mathrm{ZnO}$ film was marginally greater at $3.7 \mathrm{eV}$. The increase in the band gap is attributed to the Moss-Burstein effect and is due to the Fermi level moving into the conduction band caused by an increase in carrier concentration. ${ }^{37}$ The electrons can only be excited to levels above the Fermi level because all the states below this are occupied. Hence, the band gap increases.
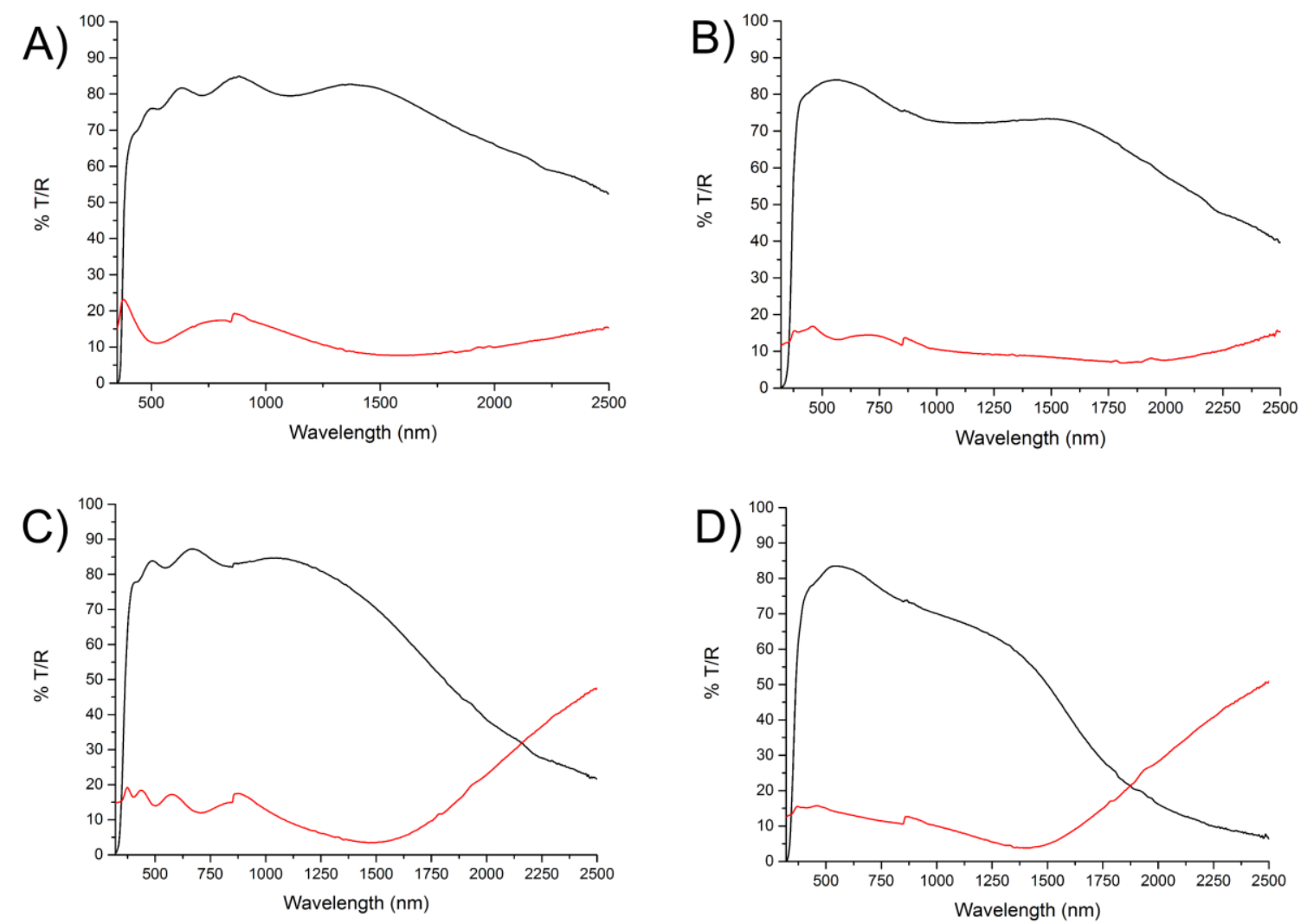

Fig. 4. The transmittance (-) and reflectance $(-)$ properties of the films grown via AACVD using diethylzinc, methanol, ammonium fluoride and trimethylaluminium: (a) ZnO, (b) F:ZnO, (c) Al:ZnO, (d) $\mathrm{Al}: \mathrm{F}: \mathrm{ZnO}$.

The $\mathrm{ZnO}$ films show a high transparency of $~ 80 \%$ at $550 \mathrm{~nm}$ in air. This is enhanced to upto $\sim 85 \%$ when the films are doped. However, no correlation was found between 
film thickness and optical properties. The reflectance properties of the $\mathrm{ZnO}$ and Al:ZnO films were as expected for a low e-material, reaching a maximum of $\sim 20 \%$ at $2500 \mathrm{~nm}$. Doping the films with fluorine or co-doping with aluminium and fluorine increased the reflectance properties to $50 \%$; this is comparable with commercial products such as F-doped $\mathrm{SnO}_{2}{ }^{38}$ The plasma edge of the Al:F: $\mathrm{ZnO}$ film had the greatest red shift $(\sim 1850 \mathrm{~nm})$ which is due to the relatively larger concentration of the charge carriers. The wavelength of the crossover is in the range that is suitable for a heat mirror as it enables the transmission of both visible and infrared radiation that would allow solar energy gain for heating purposes in cold climates. ${ }^{39}$

\section{Conclusions}

AACVD grown thin films of $\mathrm{F}$ and $\mathrm{Al}$ doped and co doped $\mathrm{ZnO}$ films were highly transparent with excellent electrical conductivities. The study found that co-doping of $\mathrm{ZnO}$ with 1 at.\% and 2 at.\% of $\mathrm{F}$ and $\mathrm{Al}$ respectively resulted in a sheet resistance of $52.8 \Omega / \square$. Co-doping also resulted in the films having a structured and scattering morphology that is ideal for photovoltaic devices. The plasma edge was shifted to lower wavelengths making it highly suitable for applications such as a heat mirror. Currently, work is underway to further improve electrical properties by efforts to increase the charge carrier concentration and thus increase electrical conductivities by using alternative dopant precursors. Attempts are also being made to shift the plasma edge to lower wavelengths to improve the films' heat mirror properties.

\section{Acknowledgements}

EPSRC are thanked for a studentship (SDP) and for grant no. EP/K001515. NSG are thanked for the glass substrates. 


\section{References}

${ }^{1}$ G. Thomas, Nature., 1997, 389, 907-908.

${ }^{2}$ A. N. Banerjee and K. K. Chattopadhyay, Prog. Cryst. Growth. Ch., 2005, 50, 52-105.

${ }^{3}$ T. Minami, Semicond. Sci. Technol., 2005, 20, S35-S44.

${ }^{4}$ N. Noor and I. P. Parkin, J. Mater. Chem. C, 2013, 1, 984-996.

${ }^{5}$ S. Kahraman, H. M. Cakmak, S. Cetinkaya, F. Bayansal, H. A. Cetinkara and H. S. Guder, J. Cryst. Growth, 2013, 363, 86-92.

${ }^{6}$ Y. Yang, S. Jin, J. E. Medvedeva, J. R. Ireland, A. W. Metz, J. Ni, M. C. Hersam, A. J. Freeman and T. J. Marks, J. Am. Chem. Soc., 2005, 127, 8796-8804.

7 C. E. Knapp, G. Hyett, I. P. Parkin, C. J. Carmalt, Chem. Mater., 2011, 23, 1719-1726.

${ }^{8}$ H. Kim, R. C. Y. Auyeung and A. Piqué, Thin Solid Films, 2008, 516, 552-5056.

${ }^{9}$ S. Jin, Y. Yang, J. E. Medvedeva, L. Wang, S. Li, N. Cortes, J. R. Ireland, A. W. Metz, J.

Ni, M. C. Hersam, A. J. Freeman and T. J. Marks, Chem. Mater., 2008, 20, 220-230.

${ }^{10}$ S. M. A. Durrani, E. E. Khawaja, A. M. Al-Shukri and M. F. Al-Kuhaili, Energ. Buildings, 2004, 36, 891-898.

11 Y. M. Guo, L. P. Zhu, J. Jiang, Y. G. Li, L. Hu, H. B. Xu and Z. Z. Ye, J. Alloy. Compd., 2014, 602, 294-299.

${ }^{12}$ M. R. Waugh, G. Hyett and I. P. Parkin, Chem. Vap. Deposition, 2008, 14, 366-372.

${ }^{13}$ Y. Liu, Y. Li and H. Zeng, Journal of Nanomaterials, 2013, 2013, 9pp.

${ }^{14}$ D. Barreca, A. P. Ferrucci, A. Gasparotto, C. Maccato, C. Maragno and E. Tondello, Chem. Vap. Deposition, 2007, 13, 618-625.

${ }^{15}$ O. Baka, A. Azizi, S. Velumani, G. Schmerber and A. Dinia, J. Mater. Sci: Mater Electron, 2014, 25, 1761-1769.

${ }^{16}$ M. Anusha and D. Arivuoli, J. Alloy. Compd., 2013, 580, 131-136.

${ }^{17}$ R. Ebrahimifard, M. R. Golobostanfard and H. Abdizadeh, Appl. Surf. Sci., 2014, 290, 252259.

${ }^{18}$ J. Hu and R. G. Gordon, J. Appl. Phys., 1992, 72, 5381-5392.

${ }^{19}$ A. R. Babar, P. R. Deshamukh, R. J. Deokate, D. Haranath, C. H. Bhosale and K. Y.

Rajpure, J. Phys. D: Appl. Phys., 2008, 41, 135404 (6pp).

${ }_{20}$ M. de la L. Olvera, A. Maldonado, J. Vega-Pérez and O. Solorza-Feria, Mater. Sci. Eng. B, 2010, 174, 42-45.

${ }^{21}$ A. C. Aragonès, A. Palacios-Padrós, F. Caballero-Briones and F. Sanz, Electrochim. Acta, 2013, 109, 117-124.

${ }^{22}$ S-M. Park, T. Ikegami and K. Ebihara, Thin Solid Films, 2006, 513, 90-94.

${ }^{23}$ C. S. McNally, D. P. Turner, A. N. Kulak, F. C. Meldrum and G. Hyett, Surf. \& Coat.

Technol., 2009, 203, 1042-1049.

${ }^{24}$ P. Marchand, I. A. Hassan, I. P. Parkin and C. J. Carmalt, Dalton Trans., 2013, 42, 94069422.

${ }^{25}$ S. basharat, C. J. Carmalt, R. Binions, R. Palgrave, I. P. Parkin, Dalton Trans, 2008, 591 595.

${ }^{26}$ B. Vidjayacoumar, D. J. H. Emslie, S. B. Clendenning, J. M. Blackwell, J.F. Britten and A. Rheingold, Chem. Mater., 2010, 22, 4844-4853.

27 J. Sakaliūnienè, J. Čyvienè, B. Abakevičienè and J. Dudonis, Acta Physica Polonica A, 2011, 120, 63-65.

${ }^{28}$ G. Walters and I. P. Parkin, Appl. Surf. Sci., 2009, 255, 6555-6560.

${ }^{29}$ M. G. Nolan, J. A. Hamilton, S. O'Brien, L. Pereira, E. Fortunato, R. Martins, I. M. Povey and M. E. Pemble, J. Photochem. Photobiol. A, 2011, 219, 10-15.

${ }^{30}$ A. Douayar, R. Diaz, F. Cherkaoui El Moursli, G. Schmerber, A. Dinia and M. Abd-Lefdil, Eur. Phys. J. Appl. Phys., 2001, 53, 20501 (4pp).

${ }^{31}$ S. J. S. Qazi, A. R. Rennie, J. K. Cockcroft and M. Vickers, J. Colloid. Interf. Sci., 2003, 338, 105-110. 
32 R. Ghosh, D. Basak and S. Fujihara, J. Appl. Phys., 2004, 96, 2689-2692.

33 J. N. Deunow, T. A. Gessert, D. M. Wood, B. Egaas, R. Noufi and T. J. Coutts, Mater. Res. Soc. Symp. Proc., 2007, 1012, Y01-08.

34 S. Karamat, R. S. Rawat, P. Lee, T.L. Tan and R. V. Ramanujan, Progress in Natural Science: Materials International, 2014, 24, 142-149.

${ }^{35}$ C. M. Muiva, T. S. Sathiaraj and K. Maabong, Ceram. Int., 2011, 37, 555-560.

${ }^{36}$ J. Tauc, Mat. Res. Bull., 1968, 3, 37-46.

37 N. Noor and I. P. Parkin, J. Mater. Chem. C, 2013, 1, 984-996.

${ }^{38}$ D. S. Bhachu, M. R. Waugh, K. Zeissler, W. R. Branford and I. P. Parkin, Chem. Eur. J., 2011,17, 11613-11621.

${ }^{39}$ C. M. Lampert, Sol. Energ. Mat. 1981, 6, 1-41. 